\title{
Article \\ Sintering High Green Density Direct Powder Rolled Titanium Strips, in Argon Atmosphere
}

\author{
Anthony Govender ${ }^{1, *}$, Clinton Bemont ${ }^{1}$ and Silethelwe Chikosha ${ }^{2}$ \\ 1 School of Mechanical Engineering, University of KwaZulu-Natal, KwaZulu-Natal 4001, South Africa; \\ BemontC@ukzn.ac.za \\ 2 Manufacturing Cluster, Council of Scientific and Industrial Research, Pretoria 0081, South Africa; \\ SChikosha@csir.co.za \\ * Correspondence: govendera2@ukzn.ac.za; Tel.: +27-031-260-1212
}

Citation: Govender, A.; Bemont, C.; Chikosha, S. Sintering High Green Density Direct Powder Rolled Titanium Strips, in Argon Atmosphere. Metals 2021, 11, 936. https://doi.org/10.3390/met11060936

Academic Editor: Janusz

Stefan Konstanty

Received: 6 April 2021

Accepted: 24 April 2021

Published: 9 June 2021

Publisher's Note: MDPI stays neutral with regard to jurisdictional claims in published maps and institutional affiliations.

Copyright: (c) 2021 by the authors. Licensee MDPI, Basel, Switzerland. This article is an open access article distributed under the terms and conditions of the Creative Commons Attribution (CC BY) license (https:// creativecommons.org/licenses/by/ $4.0 /)$.

\begin{abstract}
Presently, the majority of titanium powder metallurgy components produced are sintered under high vacuum due to the associated benefits of the vacuum atmosphere. However, highvacuum sintering is a batch process, which limits daily production. A higher daily part production is achievable via a continuous sintering process, which uses argon gas to shield the part from air contamination. To date, there has been limited work published on argon gas sintering of titanium in short durations. This study investigated the properties of thin high green density titanium strips, which were sintered at the temperatures of $1100{ }^{\circ} \mathrm{C}, 1200^{\circ} \mathrm{C}$ and $1300{ }^{\circ} \mathrm{C}$ for a duration of $30 \mathrm{~min}, 60 \mathrm{~min}$ and $90 \mathrm{~min}$ in argon. The strips were produced by rolling of $-45 \mu \mathrm{m}$ near ASTM (American Society for Testing and Materials) grade 3 hydride-dehydride commercially pure titanium powder. The density, hardness, tensile properties and microstructure of the sintered strips were assessed. It was found that near-full densities, between 96 and $99 \%$, are attainable after 30-90 min of sintering. The optimum sintering temperature range was found to be $1100-1200{ }^{\circ} \mathrm{C}$, as this produced the highest elongation of $4-5.5 \%$. Sintering at $1300{ }^{\circ} \mathrm{C}$ resulted in lower elongation due to higher contaminant pick-up.
\end{abstract}

Keywords: titanium; powder; sintering; argon; properties; strip

\section{Introduction}

Titanium is an engineering material due to its high specific strength, corrosion resistance, and having approximately $60 \%$ of the density of steel, it thus can create many weight-saving opportunities [1]. However, the use of titanium is limited, as it is significantly more costly than metals such as aluminum and steel [2]. Due to the current high cost of titanium, many initiatives have arisen which are driven towards lowering the cost of titanium, both in its extraction and processing stages. Innovative extractive processes use thermochemical or electrochemical processes that produce titanium powder by the reduction of $\mathrm{TiCl}_{4}$ and $\mathrm{TiO}_{2}$, or by electrolysis of $\mathrm{TiO}_{2}$, respectively. Some examples of these extractive processes are the $\mathrm{TiRO}^{\mathrm{TM}}$ process, the Council for Scientific and Industrial research (CSIR) process, the Armstrong process, the Albany Research Centre (ARC) process, the Ono and Suzuki (OS) process and the Fray-Farthing-Chen (FFC) process [3]. Some examples of innovative powder consolidation techniques include hot isostatic pressing, vacuum hot pressing, microwave sintering, spark plasma sintering, etc. [3].

A commonly used form of titanium is sheet, which has applications in automobiles, sports equipment, medical care products, aircraft, etc. [4]. Globally, titanium sheet is manufactured via the wrought-ingot process, which comprises of many processing steps and is discussed in detail Section 1.1. A potential alternate process for producing titanium sheet at a lower cost than the wrought-ingot process, is the direct powder rolling (DPR) and sintering process which has fewer processing steps than the wrought-ingot process, and is discussed in detail Section 1.2. The production of titanium sheet via the DPR process 
can be accomplished by either a vacuum sinter process or an inert gas sinter process, which are also discussed in Section 1.2.

The process of producing titanium sheet via DPR and vacuum sintering, which is discussed in Section 1.3, is well-established and understood. However, the sintering of titanium in an argon atmosphere has not been thoroughly investigated and understood, and there are aspects such as sintering of high-density DPR strips in short durations that are still to be investigate; this is discussed in Section 1.4. It is beneficial to research the aforementioned research gap, because if it can be demonstrated that the argon gas sintering process can produce titanium sheet properties that are equivalent to vacuum-sintered sheet, the production capacity of the DPR process will increase, as continuous furnaces have higher productivities than batch (vacuum) furnaces [5]. This is highly likely to significantly lower the cost of the sheet produced.

The current cost of titanium sheet that is produced from the wrought-ingot process, in the size range of $1 \mathrm{~mm}$ or less, is between 100 and $200 \$ / \mathrm{kg}$, based on 2020 Chinese prices [6]. In comparison, the cost of hydride-dehydride titanium (Ti-HDH) powder varies between 25 and $75 \$ / \mathrm{kg}$, based on 2020 Chinese prices [6]. Thus, there is significant room for DPR titanium sheet to be potentially cost-competitive against titanium sheet produced from the wrought-ingot process.

\subsection{Titanium Sheet Production from Ingot}

Presently, titanium sheet is produced by the wrought-ingot process, which is illustrated in Figure 1. This process comprises many heating and rolling steps of ingot titanium, which is a significant contributing factor to the high cost of titanium sheet. It has been shown that $47 \%$ of the final cost of titanium sheet is from the cost of converting the ingot to sheet [7]. There are many commercial producers of titanium sheet that produce titanium sheet by the wrought-ingot process, such as TIMET [8] (American manufacturer) and Nippon Titanium [9] (Japanese manufacturer). As illustrated in Figure 1, this is a time-consuming and energy-intensive process that involves several steps, thus, there is an opportunity for the cost reduction in the manufacturing process, if the number of steps in the production process can be reduced.

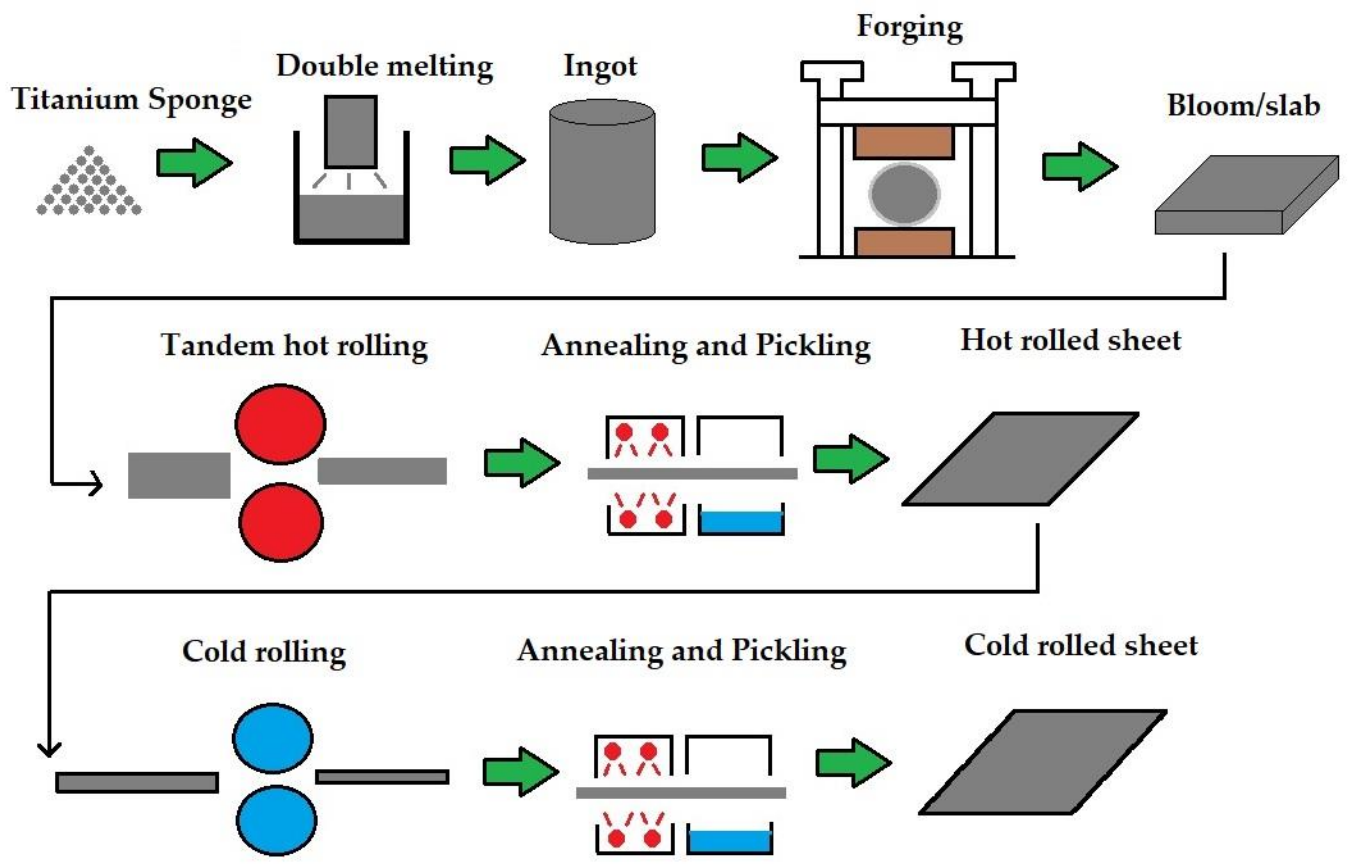

Figure 1. Titanium sheet production via the wrought process (adapted from [10]). 


\subsection{Titanium Sheet Production from Powder}

The roll compaction of titanium powder and sinter routes to produce sheet are illustrated in Figure 2, and are potential alternative routes to produce titanium sheet, in fewer production stages than the wrought-ingot sheet production process. During the DPR process, titanium powder is rolled compacted to a high-density sheet, typically referred to as green sheet in the powder metallurgy (PM) field. The green sheet is thereafter sintered in a high-vacuum or inert gas furnace to created bonds between the compacted powder particles, which increases the strength and ductility of the sheet. As illustrated in Figure 2, the use of argon gas to shield the strip from air allows the sintering process to be continuous, whereas the use of vacuum atmosphere is limited to batch furnaces.
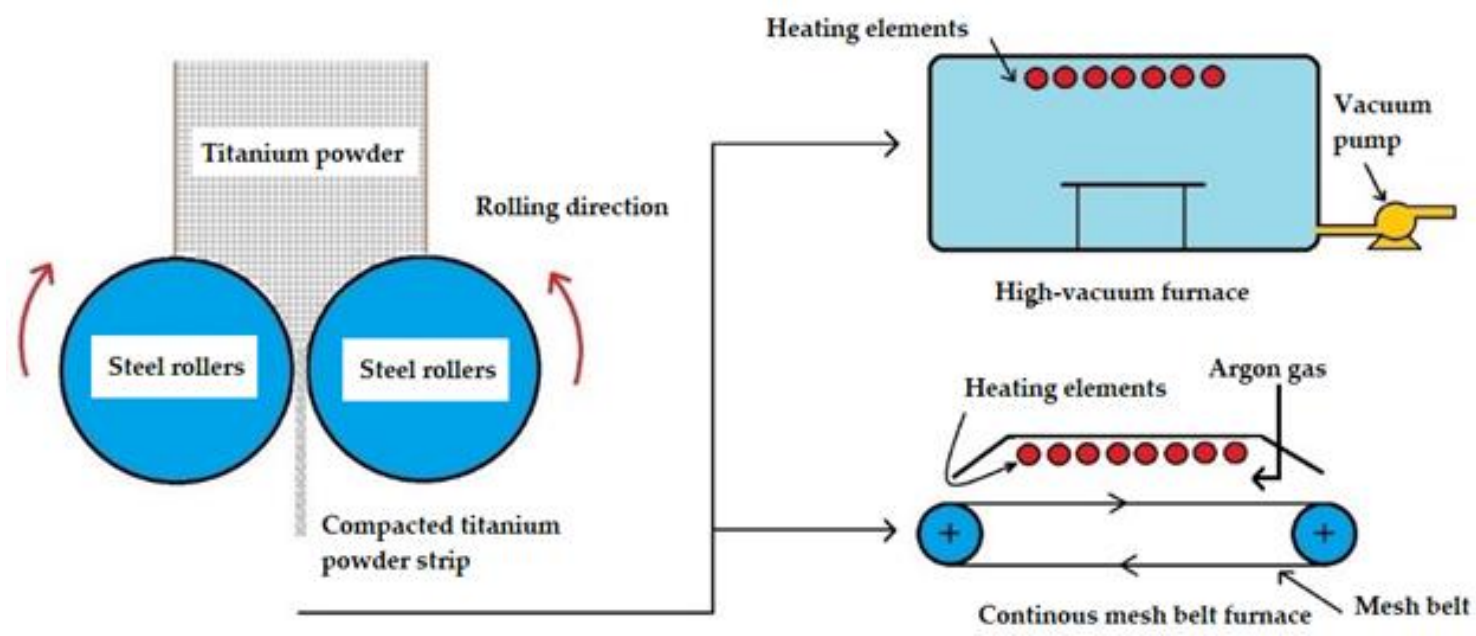

Figure 2. The direct powder rolling process and sintering furnaces (adapted from [11,12]).

\subsection{Vacuum Sintering}

It has been shown in numerous studies that titanium sheet can be produced by the roll compaction and vacuum sinter approach, which meets ASTM standards [13-16]. For example, in a joint study by personnel from Ametek, the Commonwealth Scientific and Industrial Research Organization (CSIRO) and Oak Ridge National Laboratory, three methods of titanium sheet production were investigated [17]. The first method involves cold rolling titanium powder to a green sheet, followed by vacuum sintering, a cycle which is repeated 5 times to achieve a full-density sheet. The technique of applying multiple rolling and annealing cycles to achieve full density involves more process steps and also creates a textured sheet, i.e., a variation of properties in the longitudinal and transverse directions of the sheet [18], which is not ideal for commercial products.

The second method involves a vacuum-sintered green sheet, which is thereafter hot rolled to produce a full-density sheet. The third method encapsulates many layers of titanium green sheet in an evacuated steel can, which is thereafter hot rolled. All three methods were found to produce titanium sheet that meets ASTM B265 standards. From the above studies, it is evident that vacuum sintering can produce titanium sheet that meets industry standard, and thus the vacuum sinter method is well-understood and established.

\subsection{Argon Gas Sintering}

In a patent by the inventors V.S. Moxson and V.A. Duz of Advanced Materials Products Inc. (ADMA) [18], an initial cold rolling process of blended titanium alloy powder, e.g., Ti-6AL-4V, is described, which produces a green sheet density of $60 \pm 20 \%$. Density is expressed as a percentage of the theoretical density. The green sheet is thereafter rerolled to produce a green sheet with final density of $99-100 \%$. The green sheet is sintered in a vacuum furnace or on a continuous belt furnace under an inert atmosphere [18]. However, only the vacuum-sintered material properties of the high-density green sheet of alloyed 
titanium were reported. There was no report of the material properties that can be achieved during continuous inert gas sintering of the commercially pure (CP) titanium green sheet. Thus, there is a need to further research the material properties achievable via inert gas sintering of titanium green sheet.

The chemicals manufacturer DuPont in the 1950s rolled a sodium-reduced titanium powder to a green density of $90 \%$, aided by particle-size optimization. The green sheet was thereafter sintered in a continuous furnace under an inert gas atmosphere [19]. The produced sheet had high ductility and a superior surface finish. The sintering process parameters that affected the final hardness of the sheet, were identified as the atmosphere purity and the time at temperature. Although the properties of the sheet produced were good, the sintered sheet was not used commercially, as there was significant chloride content in the sheet which created problems during welding. The temperatures used during this continuous sintering process and the time duration of sintering were not reported. Thus, there is a need to investigate and publish the effect of these parameters.

Researchers at Auckland University investigated the effect of sintering titanium in an argon atmosphere [20]. In the study, $-75 \mu \mathrm{m}$ Ti-HDH powder was compacted to a green density of $75 \%$ by die compaction. Thereafter, the compacts were sintered at each temperature of $1100{ }^{\circ} \mathrm{C}, 1200{ }^{\circ} \mathrm{C}$ and $1400{ }^{\circ} \mathrm{C}$ for 4,6 and $8 \mathrm{~h}$, in an argon atmosphere of $99.99 \%$ purity. The compacts were 5 to $8 \mathrm{~mm}$ in thickness. During the initial stage of the sintering cycle, the compacts were heated in a vacuum atmosphere of $0.01 \mathrm{~Pa}$ to release volatile matter that is present in the compact, commonly referred to as off-gassing. Although this is good practice, the sintering cycle effectively consisted of a vacuum and an argon gas sintering process. Further work should thus investigate the properties of titanium powder compacts sintered only in an argon atmosphere.

In the study by Auckland University [20], long sintering durations were investigated, which were in excess of $4 \mathrm{hrs}$. However, future work should investigate shorter sinter durations as they are preferred for continuous sintering cycles. Furthermore, it would have been more beneficial to sinter green compacts with densities greater than $75 \%$, as higher as-sintered properties are likely thereby attained [21]. Higher green density compacts generally have less exposed area, which reduces the compact contact area with the furnace atmosphere and thus reduces contamination pick-up by the compact. Thus, based on the aforementioned identified shortcomings in the study by Auckland University [20], there is a need to investigate the properties of green titanium compacts which have a green density in excess of $75 \%$, that are sintered over short durations. In addition, sintering should be conducted in an argon atmosphere only without vacuum off-gassing, as this method is more representative of a continuous inert gas sintering process.

In a recent study by N.S. Muchavi [22], $-150 \mu \mathrm{m}$ and $-45 \mu \mathrm{m}$ Ti-6Al-4V powders were roll compacted to a green density of $85 \%$ and sintered under an argon atmosphere. The powders were produced by blending a master alloy powder with titanium powder. Sintering temperatures and durations in the study ranged from $1200{ }^{\circ} \mathrm{C}$ to $1400{ }^{\circ} \mathrm{C}$ and 2 to $4 \mathrm{~h}$, respectively. The highest sintered density produced in the study by N.S. Muchavi was 95 to $96 \%$ after 2 to $3 \mathrm{~h}$ of sintering. The results of this study are highly relevant to DPR, but it is also useful to investigate altered experimental parameters, particularly increased green strip densities $>90 \%$, in future. This will significantly improve as-sintered properties towards achieving final densities and properties closer to billet rolled titanium alloy sheet.

In summary, based on the comparison of Sections 1.3 and 1.4, it appears that vacuum sintering of titanium is better established and understood than inert gas sintering of titanium, and therefore sintering of titanium in argon atmosphere should be further explored. There exists a need to further investigate the properties of high green density ( 90\%) titanium DPR strips which are sintered at high temperatures over a range of comparatively short durations, under an argon atmosphere, which is the scope of this study. 


\section{Materials and Methods}

\subsection{Titanium Powder Characteristics}

A $-45 \mu \mathrm{m}$ Ti-HDH powder was roll compacted to produce the titanium strips. The Ti-HDH powder was purchased from Baoji Lihua Non-ferrous Metals Co., Ltd. (Baoji, Shaanxi, China), and the as-supplied chemical composition of the powder is tabulated in Table 1. As per the chemical composition of ASTM grade 3 titanium, also presented in Table 1, the titanium powder used in this study was near that of ASTM grade 3 titanium.

Table 1. Impurity content of the supplied $-45 \mu \mathrm{m}$ Ti-HDH powder and ASTM grade 3 titanium. HDH: hydride-dehydride. ASTM: American Society for Testing and Materials.

\begin{tabular}{cccccc}
\hline Titanium Product & Fe (wt.\%) & C (wt.\%) & N (wt.\%) & H (wt.\%) & O (wt.\%) \\
\hline$-45 \mu$ m powder [23] & 0.016 & 0.003 & 0.014 & 0.025 & 0.35 \\
ASTM Grade 3 [24] & $\leq 0.3$ & $\leq 0.08$ & $\leq 0.05$ & $\leq 0.015$ & $\leq 0.35$ \\
\hline
\end{tabular}

An analysis of the powder particle size distribution (PSD) was conducted on a MicroTrac S3500 laser diffraction particle size analyzer (S3500, MicroTrac, York, PA, USA). The powder PSD is illustrated in Figure 3, and the D10, D50 and D90 percentiles of the powder are tabulated in Table 2. The PSD results and percentile values confirm that a large percentage, approximately $90 \%$, of the powder particles are within the $-45 \mu \mathrm{m}$ rating.

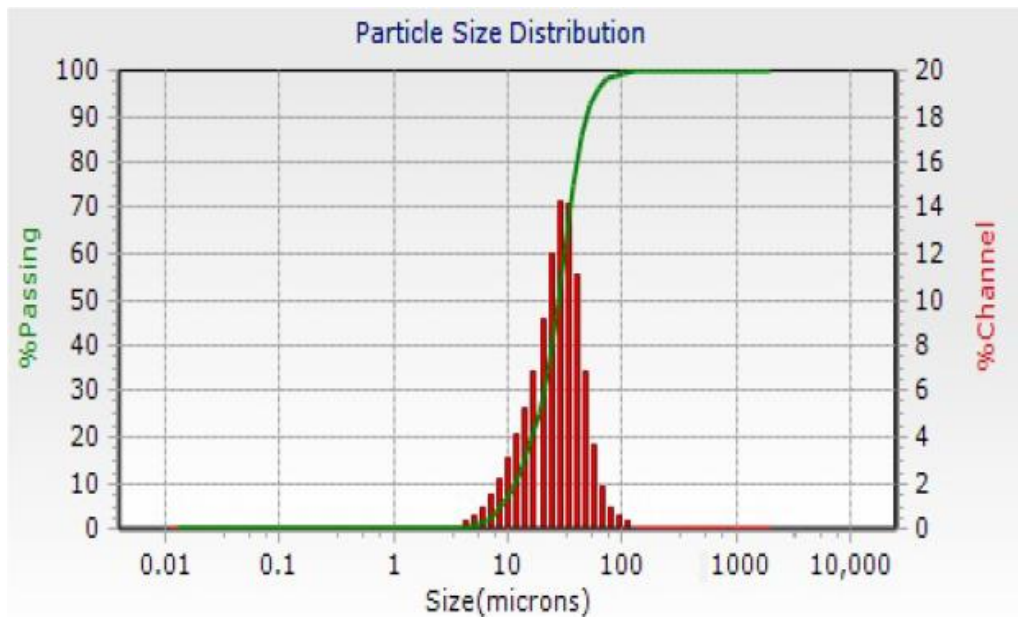

Figure 3. Particle size distribution of the $-45 \mu \mathrm{m}$ Ti-HDH (hydride-dehydride) powder.

Table 2. Particle size distribution percentiles of the $-45 \mu \mathrm{m}$ Ti-HDH powder.

\begin{tabular}{ccc}
\hline D10 $(\mu \mathrm{m})$ & D50 $(\mu \mathrm{m})$ & D90 $(\mu \mathrm{m})$ \\
\hline 11.55 & 27.37 & 48.33 \\
\hline
\end{tabular}

A scanning electron microscope (SEM) image of the Ti-HDH powder used in this study is illustrated in Figure 4. The image was produced by a JOEL JSM-6510 SEM (JSM-6510, JOEL, Tokyo, Japan) in secondary electron image mode. The angular shape of the powder particles observed in Figure 4 is characteristic of Ti-HDH powder produced from Kroll sponge [25]. The angular nature of the powder particles assists in particles interlocking during powder rolling, which increases green strip density. 


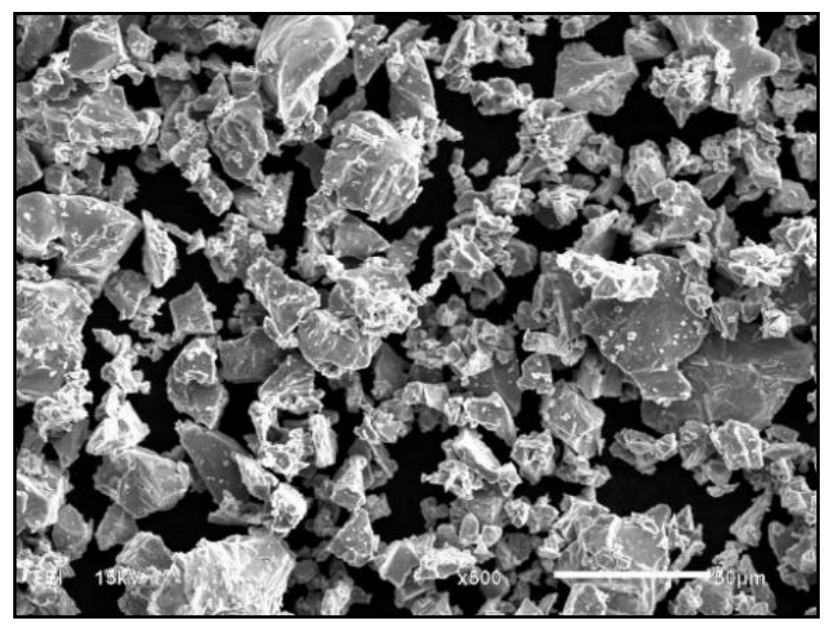

Figure 4. An SEM (scanning electron microscope) image at $500 \times$ magnification of the $-45 \mu \mathrm{m}$ Ti-HDH powder used in this study.

\subsection{The Powder Rolling and Sintering Processes}

The titanium powder was rolled into strips by two horizontally mounted steel rollers of $80 \mathrm{~mm}$ diameter, only one roller of the mill was driven, at a speed of $14 \mathrm{rpm}$. The strips were rerolled to a green density of $4.04 \mathrm{~g} / \mathrm{cm}^{3}$, i.e., $89.8 \%$ of the theoretical density of titanium. The final dimensions of the strips were $250 \mathrm{~mm}$ in length, $40 \mathrm{~mm}$ in width and $0.33 \mathrm{~mm}$ in thickness. The titanium strips were sintered in a horizontal tube furnace (Brother Furnace Co., Ltd., Zhengzhou, China). A high purity alumina (99.7\%) furnace tube was used, which is stable at high temperatures and does not chemically react with the titanium strip during sintering. The temperature of the furnace hot zone was measured to an accuracy of $\pm 1{ }^{\circ} \mathrm{C}$ by a Type-S thermocouple to ensure accurate results. The green titanium strips were placed on a smooth molybdenum boat of $99.95 \%$ purity, and inserted into the furnace tube. The smooth surface of the molybdenum ensured that longitudinal and transverse shrinkage of the strip was not restricted during sintering.

Prior to the titanium strips being heated, the furnace tube was evacuated whilst at room temperature to a vacuum level of $10^{-2} \mathrm{~Pa}$ by a vacuum pump. Thereafter, the tube was filled with a high grade of argon gas of $99.999 \%$ purity, to an absolute pressure of $110 \mathrm{kPa}$. This cycle was repeated twice to ensure that the tube volume was purged of atmospheric air molecules and particles. During the sintering cycle there was no further argon gas flow into the tube. The impurity composition of the argon gas used in this study is presented in Table 3.

Table 3. Argon gas impurities.

\begin{tabular}{ccccc}
\hline Argon Gas Grade & $\mathbf{H}_{\mathbf{2}} \mathbf{O}(\mathbf{p p m})$ & $\mathbf{O}_{\mathbf{2}}(\mathbf{p p m})$ & $\mathbf{N}_{\mathbf{2}}(\mathbf{p p m})$ & $\mathbf{C H}_{4}(\mathbf{p p m})$ \\
\hline $99.999 \%[26]$ & $<3$ & $<2$ & $<5$ & $<0.5$ \\
\hline
\end{tabular}

The general profile of the sintering cycle that was used to sinter the green titanium strips is illustrated in Figure 5. The heating rate of the sintering cycle gradually increases from $7{ }^{\circ} \mathrm{C} / \mathrm{min}$ to $9^{\circ} \mathrm{C} / \mathrm{min}$ to avoid cracking of the alumina tube by thermal shock, and $10^{\circ} \mathrm{C} / \mathrm{min}$ is the maximum heating rate achievable by the tube furnace. On completion of the heating cycle, the tube was carefully cooled at a rate of $-9{ }^{\circ} \mathrm{C} / \mathrm{min}$ to $700^{\circ} \mathrm{C}$, and thereafter the tube cooled naturally to room temperature. Below $700{ }^{\circ} \mathrm{C}$, the alumina tube cooled naturally at a rate $>-10{ }^{\circ} \mathrm{C} / \mathrm{min}$, hence, there was no heat input required from the furnace. The sintered strips were removed from the tube furnace once they reached room temperature. 


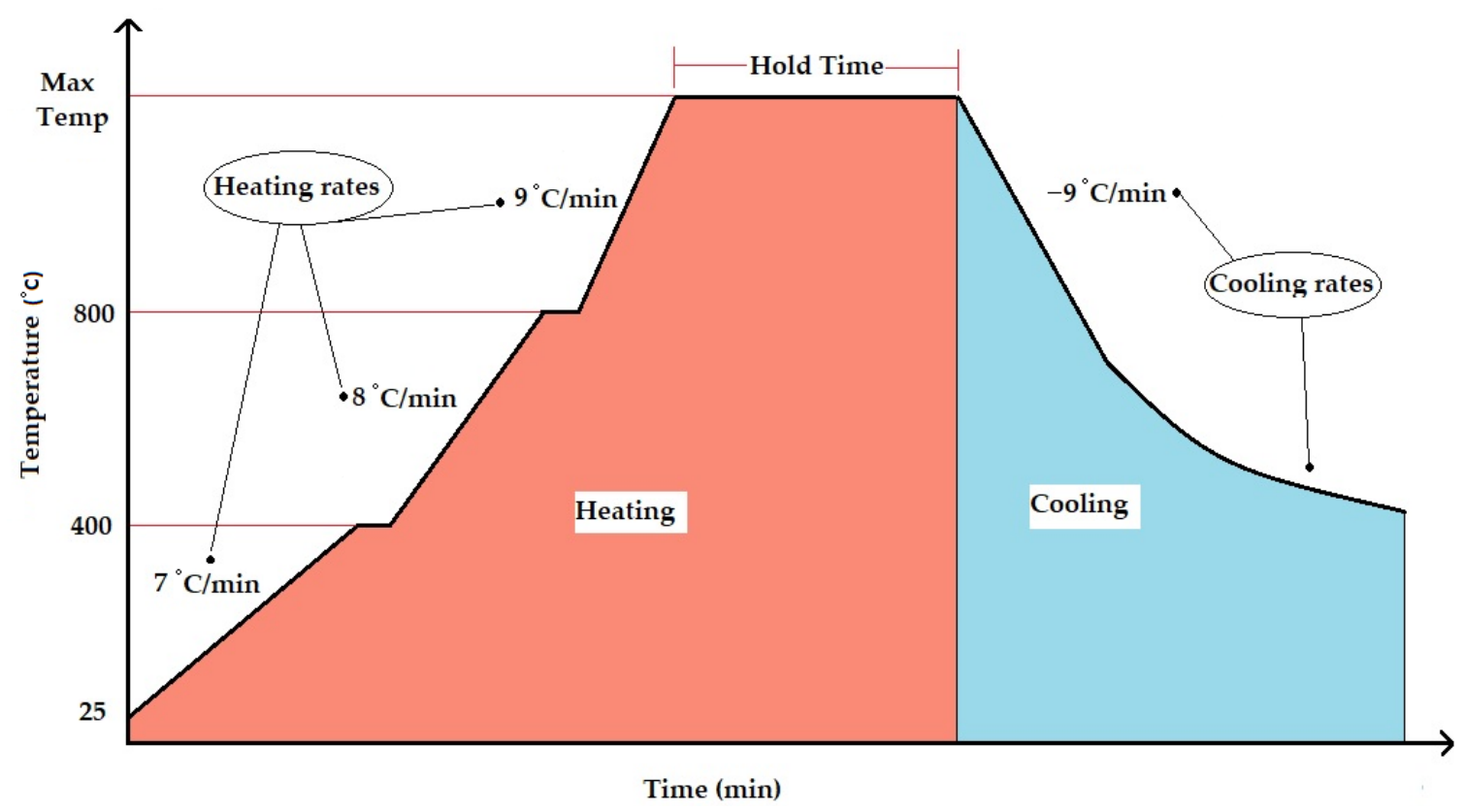

Figure 5. The general profile of the sintering cycle used in this study.

Sintering temperatures of $1100{ }^{\circ} \mathrm{C}, 1200^{\circ} \mathrm{C}$ and $1300^{\circ} \mathrm{C}$ were investigated in this study. The green titanium strips were held at each of the specified maximum temperatures, in separate tests, for $30 \mathrm{~min}, 60 \mathrm{~min}$ and $90 \mathrm{~min}$. The experimental test plan for this study is presented in Table 4 . To ensure the reliability of results, four experiments were conducted for each test point in the experimental plan.

Table 4. Experimental test plan.

\begin{tabular}{rrcc}
\hline Temperature & $\mathbf{1 1 0 0}{ }^{\circ} \mathbf{C}$ & $\mathbf{1 2 0 0}{ }^{\circ} \mathbf{C}$ & $\mathbf{1 3 0 0}{ }^{\circ} \mathbf{C}$ \\
\hline \multirow{3}{*}{ Time (min) } & 30 & 30 & 30 \\
& 60 & 60 & 60 \\
& 90 & 90 & 90 \\
\hline
\end{tabular}

\subsection{Sintered Strip Property Analyses}

2.3.1. Strip Density and Vickers Microhardness

The density of the sintered and green titanium strips were measured according to the standard ASTM B962-08b [27], by using a Sartorius analytical balance (BP 110S, Sartorius, Goettingen, Germany) which has a resolution $0.1 \mathrm{mg}$. Vickers microhardness testing was conducted on the sintered strips according to standard ASTM B933-16 [28], on an EMCO-TEST DuraScan 20 hardness tester (EMCO-TEST, DuraScan 20, Kuchl, Austria). The microhardness testing was conducted near the surface edge of the width cross section of the strips, with a $50 \mathrm{gf}$ test load. Twenty points were tested on each sintered strip.

\subsubsection{Tensile Testing}

The tensile test specimens were cut from the sintered titanium strips along the direction of rolling, according to the standard tensile test specimen dimensions in ASTM 8/E 8M08 [29]. The test specimens have an overall length of $200 \mathrm{~mm}$, a gage length of $50 \mathrm{~mm}$ and a reduced section width of $12.5 \mathrm{~mm}$. The test specimens were loaded at a cross head speed of $1.2 \mathrm{~mm} / \mathrm{min}$ until failure, by an Instron $5500 \mathrm{R}$ tensile tester (Instron, Norwood, MA, USA). The tensile strain was measured by a contact type 1 extensometer, which met the requirements of a class B-2 extensometer according to the standard ASTM E83-16 [30]. The elastic moduli of the sintered titanium strips were calculated according to the methods described in ASTM E111-04 [31], by determining the slope of the stress-strain curve for 
forces below the proportional limit. The elastic moduli were determined for strain values of less than $0.25 \%$ to avoid for correction of reduction in the tensile specimen area.

\subsubsection{Microstructural Characterization}

A width cross section of each of the sintered titanium strips was hot-compressionmounted in resin, via a Struers LaboPress 3 hot mounting machine (LaboPress 3, Struers, Copenhagen, Denmark). The specimens were metallographically prepared by initially grinding the specimens on $\mathrm{SiC}$ abrasive paper lubricated with water, using the following sequence of papers: P220, P320, P500, P1200, P2000 and P4000 [32]. The specimens were thereafter chemically and mechanically polished with a mixture of hydrogen peroxide ( $30 \%$ concentration) and colloidal silica solution, which contains $0.04 \mu \mathrm{m}$ grit. The mixture was prepared by mixing $40 \mathrm{~mL}$ hydrogen peroxide with $260 \mathrm{~mL}$ colloidal silica solution [33]. The microstructure of the polished specimens was thereafter viewed under cross-polarized light by using a Nikon Eclipse MA200 optical microscope (Nikon, Tokyo, Japan). The specimens were etched with Kroll's reagent, which is a mixture of $2 \mathrm{~mL}$ hydrofluoric acid (HF):6 mL nitric acid $\left(\mathrm{HNO}_{3}\right): 100 \mathrm{~mL}$ distilled water, for a period of $20 \mathrm{~s}$ [34]. The grain size of the sintered strips was determined on the etched specimens, according to the linear intercept method described in the standard ASTM E112-13 [35]. Five fields on each specimen were assessed at $100 \times$ magnification, with 60 or more intercepts on each test line.

\section{Results and Discussion}

A typical green strip and sintered strip produced in this study are illustrated in Figure 6. The lustrous appearance of the green strip is indicative of the high green density of the strip, and the metallic shine of the sintered strip is indicative of the minimal surface contamination from the argon atmosphere.

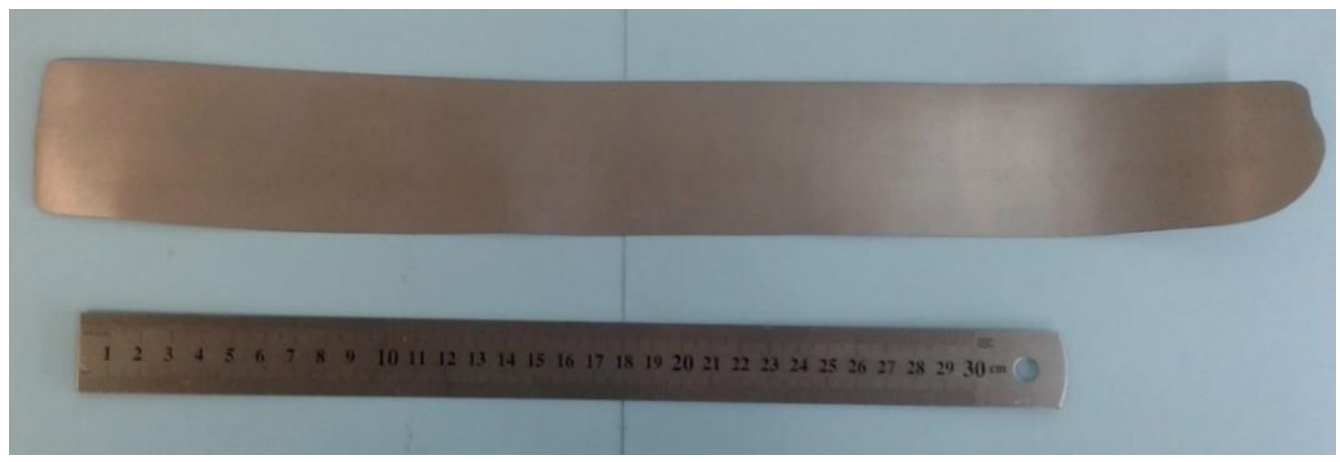

(a)

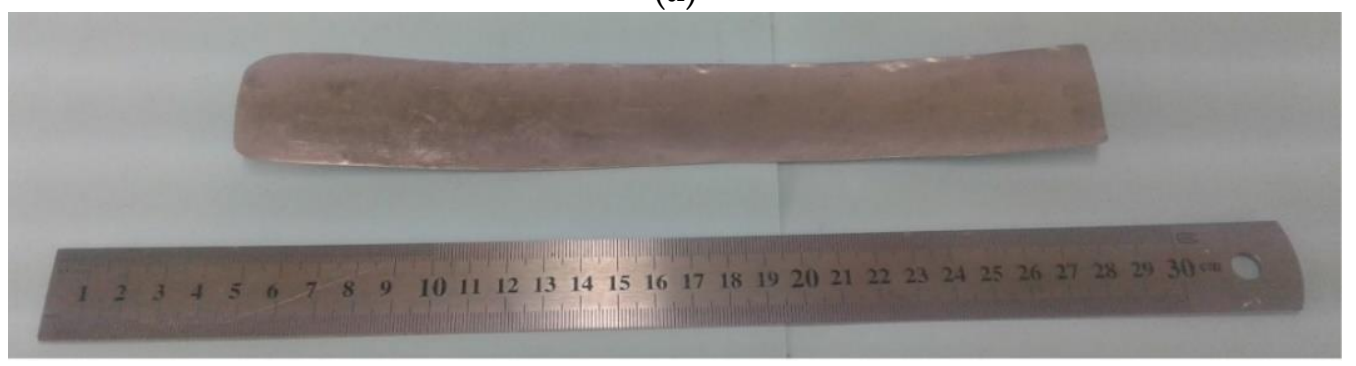

(b)

Figure 6. Typical titanium strips produced in this study: (a) a green titanium strip; (b) a sintered titanium strip.

The surface of a green strip and a sintered strip as viewed under a SEM are illustrated in Figure 7. The green strip surface has randomly distributed surface pores amongst densely packed deformed titanium powder particles. The powder particles were deformed by the cold rolling process. The fine line striations on the surface of the green strip were produced by the repeated cold rolling operations. It is also clear from the green strip image 
that some deformed particles cover or partially cover interparticle surface pores. This is beneficial as the closure and size reduction of the surface pores reduces the amount of argon gas that enters the strip during sintering, which thus improves as-sintered properties. The sintered strip surface image indicates the large reduction in the number of surface pores from the green state. Grain boundaries are also visible on the sintered strip surface, which indicates a high state of density.

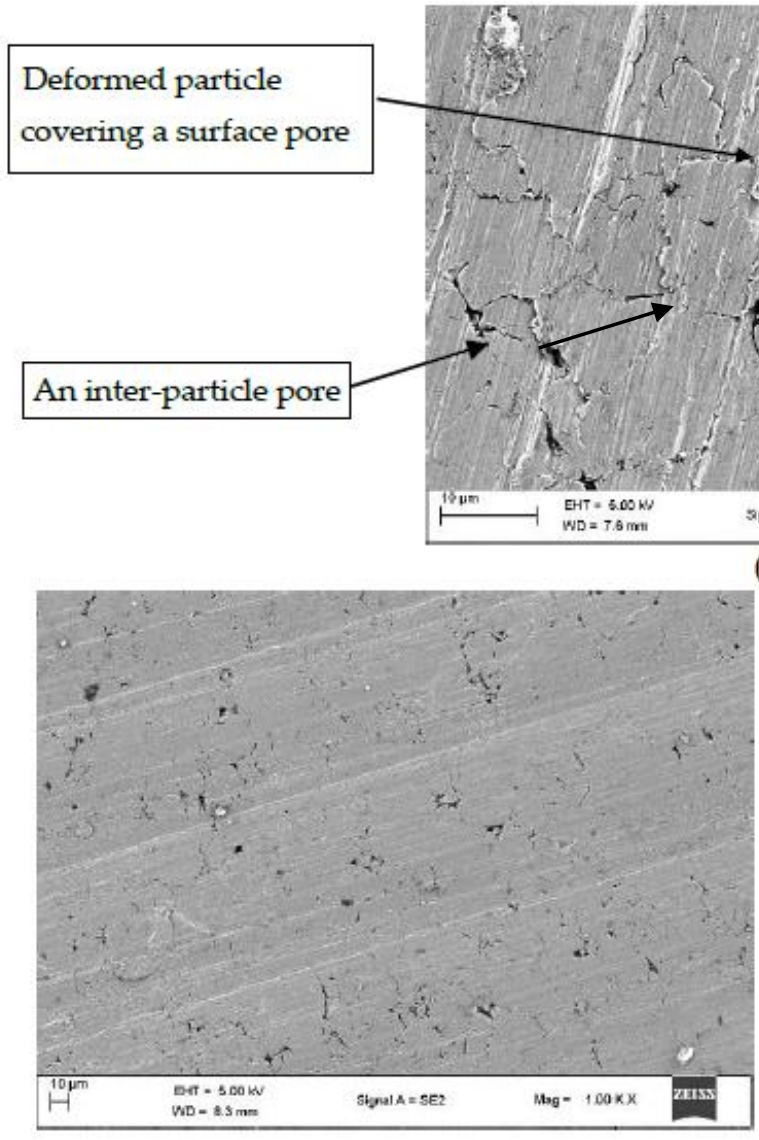

(b)

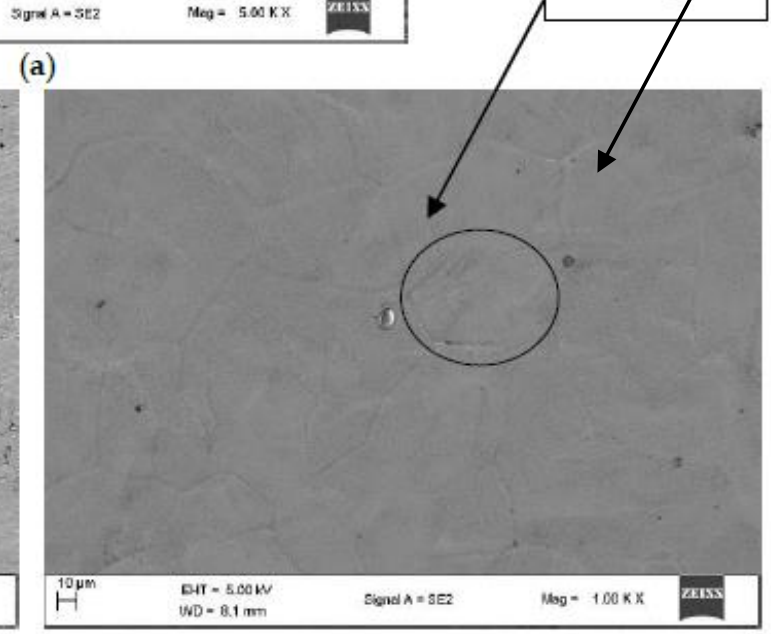

(c)

Figure 7. DPR (direct powder rolling) titanium strip surfaces: (a) green strip surface at $5000 \times$ magnification; (b) green strip surface at $1000 \times$ magnification; (c) sintered strip surface at $1000 \times$ magnification.

\subsection{Strip Density}

The average (mean) density values of the sintered strips are illustrated in Figure 8, along with the standard deviation of the results. From the results in Figure 8 it is observed that the sintered density increased with an increase in sintering time and temperature. In general, the sintered strips achieved high levels of sintered density. The strips that were sintered at $1300{ }^{\circ} \mathrm{C}$ for $90 \mathrm{~min}$ reached near-full density ( 99\%). The high density of the sintered strips is also confirmed by observing the low levels of porosity present in the microstructural images of the sintered strips in Section 3.4. 


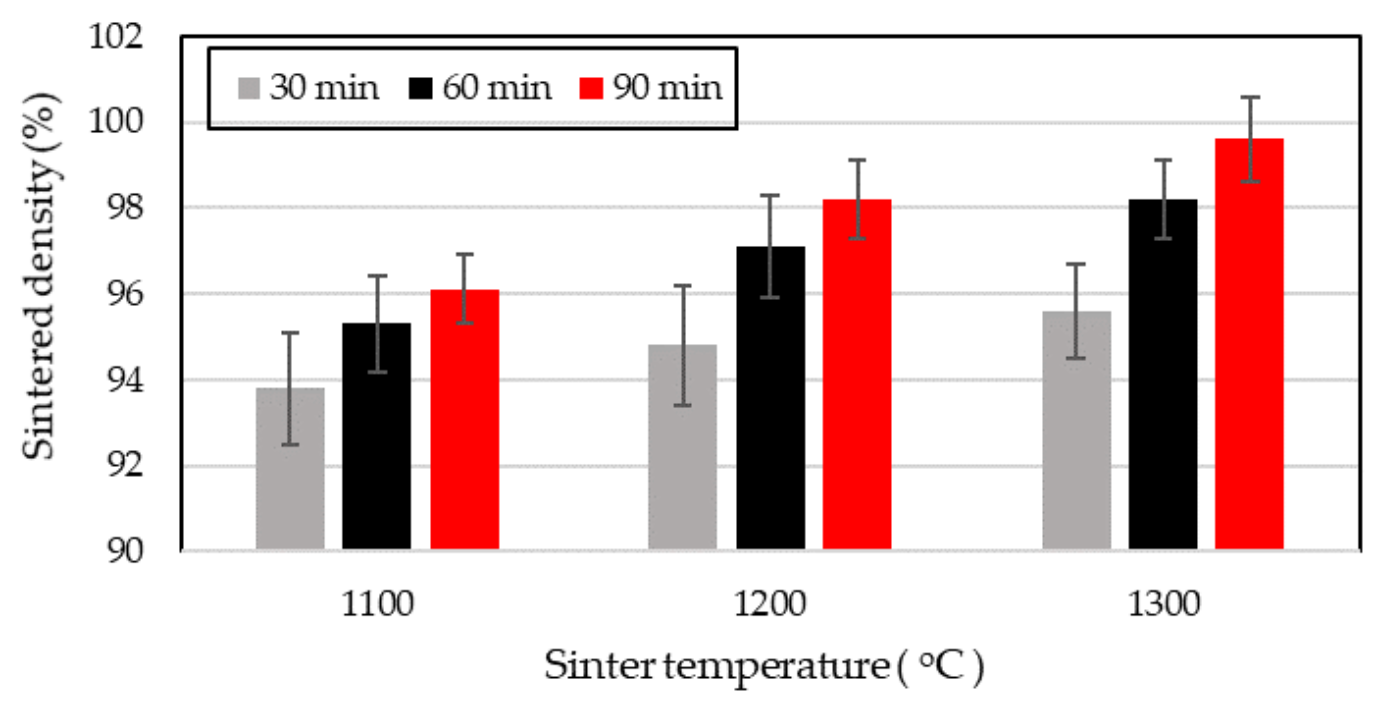

Figure 8. Sintered density of the titanium strips.

It is also noted that higher sintering temperatures caused a greater densification rate, and most of the strip densification occurs during the first 30 to $60 \mathrm{~min}$ of sintering. Sintering at temperatures over $1300{ }^{\circ} \mathrm{C}$ could not be investigated as the tube furnace that was used in this study has a maximum temperature limit of $1300{ }^{\circ} \mathrm{C}$.

The fine powder used in this study is a factor which resulted in the high sintering rates achieved. A fine powder was selected for this study, as fine powders achieve higher sintering rates than coarse powders, according to the scaling law [36]. Higher sintering rates imply shorter required sintering times, which favors a continuous sintering process. It has been shown that under the same compaction pressure, fine powders generally attain lower green density than coarse powders, however, under the same sintering conditions, the fine powder compact attains a higher sintered density than the coarse powder compact [37,38].

\subsection{Vickers Microhardness}

As the strips in this study did contain pores, a microhardness test was selected rather than a macrohardness test. Microhardness testing is advantageous over macrohardness testing as they use low test loads which reduces the effect of the pores on the material hardness measurement [28]. The hardness testing were conducted on the strip cross-section, near the surface of each strip, as illustrated in Figure 9. The hardness tests were conducted near the surface of the strips, as the surface is the most affected region by atmosphere contamination. It has been shown experimentally that the surface of a sintered component shields the inner material of the component from atmospheric contamination, and as a result, the surface is more contaminated than the inner section of the material [20]. All specimens were measured at the same depth below the surface edge. The mean and standard deviation of the results from the microhardness Vickers tests are displayed in Figure 10.

The titanium powder that was used to produce the strips has an approximate hardness of $208 \mathrm{HV}$, estimated from Brinell hardness of 200 [39]. It is observed from the results that sintering increased the strip hardness. The hardness of commercially pure (CP) titanium generally increases due to an increase in interstitial contamination, with interstitial elements such as oxygen, nitrogen, carbon, etc. [40]. The argon atmosphere used in this study contained impurities such as oxygen, nitrogen, carbon, etc., as listed in Table 3. It is likely that the titanium strips absorbed these impurities from the argon atmosphere, which is the reason for the increase in hardness. 


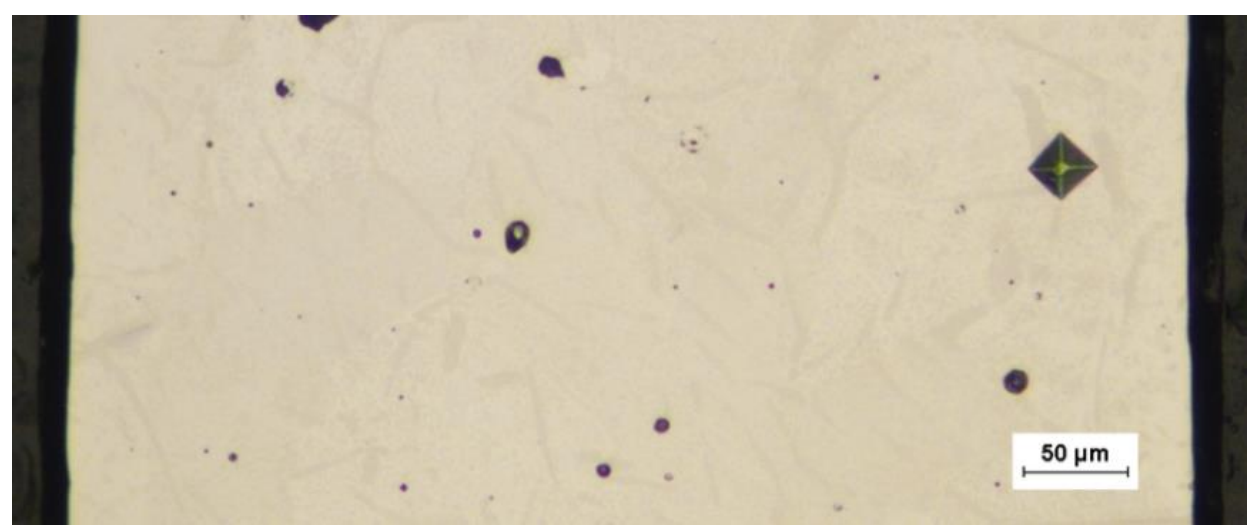

Figure 9. A typical micro Vickers indentation near the surface of a sintered titanium strip.

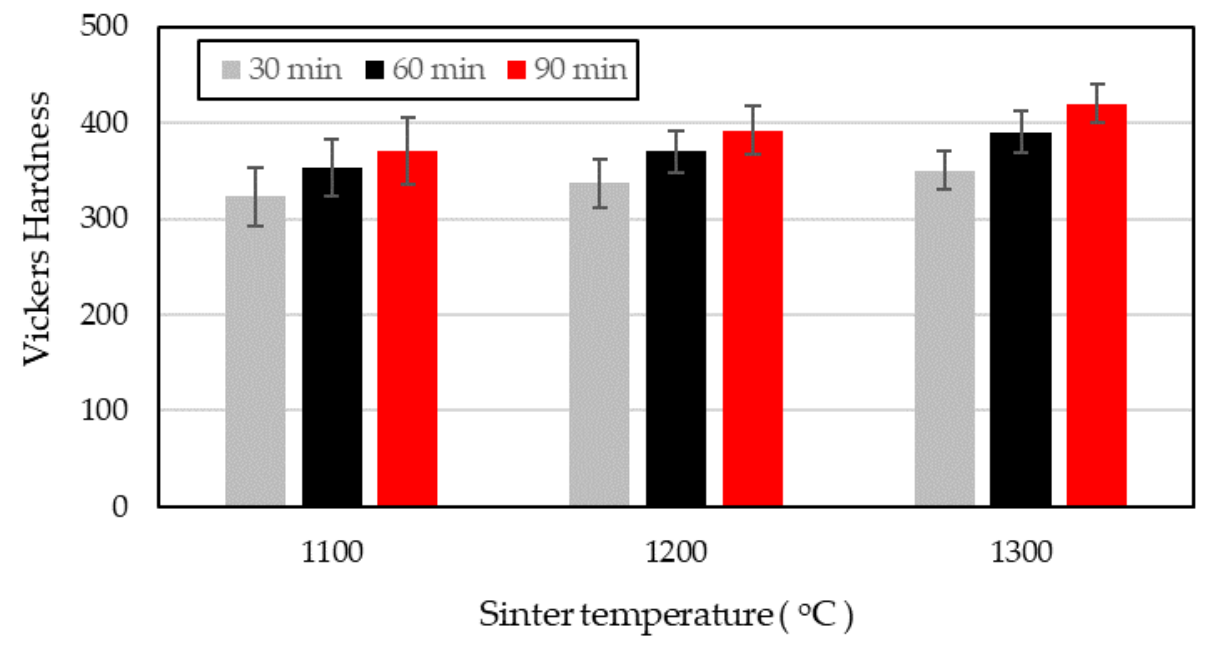

Figure 10. Surface hardness of the sintered titanium strips.

It was also found that an increase in the sintering temperature and time increased the surface hardness of the sintered strips. This is because higher sintering temperatures increased the reactivity of the strips, which resulted in the higher contamination absorption, and thus an increased hardness. Thus, the strips which were sintered at $1300{ }^{\circ} \mathrm{C}$, had the greatest contamination absorption and hence the greatest hardness. This effect can also be understood by examining the oxygen and nitrogen diffusion coefficients in titanium, which increase with an increase in temperature [41,42].

Oxygen, for example, experiences the following diffusion coefficients in titanium. The oxygen diffusion coefficient (ODC) in titanium at $1100{ }^{\circ} \mathrm{C}$ is approximately $4 \times 10^{-12} \mathrm{~m}^{2} / \mathrm{s}$ [42] At $1300{ }^{\circ} \mathrm{C}$, the $\mathrm{ODC}$ in titanium is approximately 10 times that at $1100{ }^{\circ} \mathrm{C}$, and at $1200{ }^{\circ} \mathrm{C}$, the $\mathrm{ODC}$ in titanium is approximately 3.75 times that at $1100{ }^{\circ} \mathrm{C}$ [42]. This implies that higher temperatures caused the titanium strips to absorb more oxygen from the argon atmosphere. The contamination pickup by the strips can be reduced by the use of contamination getters; however, their usage does influence the sheet production process cost [43].

\subsection{Tensile Properties}

\subsubsection{Tensile Elongation}

The tensile elongation of the sintered strips is presented in Figure 11. The best elongations that were produced in this study are in the range of $4.5 \%$ to $5.5 \%$. In comparison to the minimum required tensile elongation of ASTM grade 3 titanium which is $18 \%$, the elongation produced in this study is low. In general, all the strips that were sintered in this study had absorbed significant contamination from the argon atmosphere, as confirmed by the hardness testing, which contributed to the low elongation. The contamination in the 
form of oxygen, nitrogen and carbon atom, occupies the octahedral interstitial sites in the alpha phase of titanium, which has a hexagonal close-packed (HCP) crystal structure. The occupation of these lattice interstitial sites distorts the HCP lattice and thus hinders the movement of dislocations on the $\{10 \overline{1} 0\}\{10 \overline{1} 1\}\{0001\}$ slip planes, which reduces the strip ductility. [44]

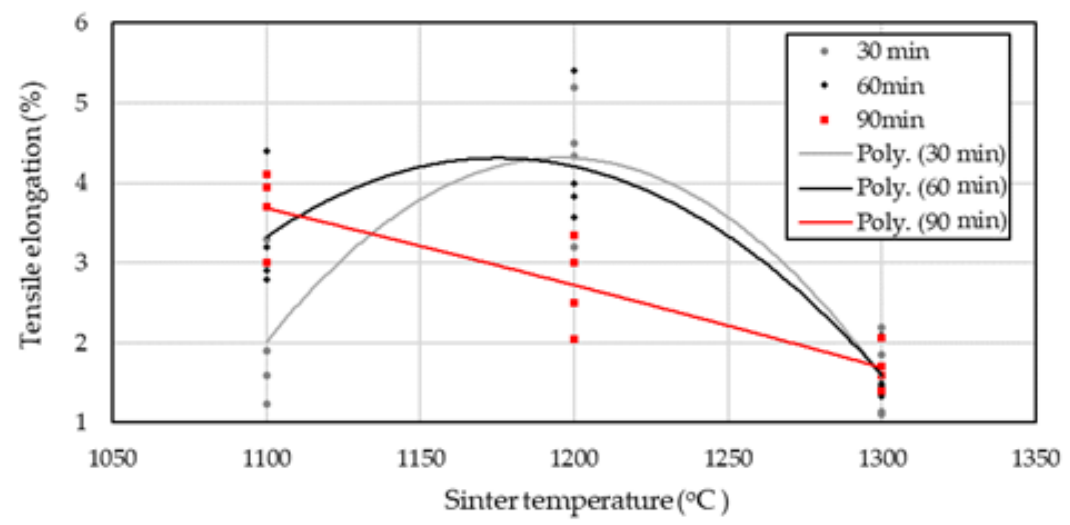

Figure 11. Tensile elongation of sintered titanium strips.

The grain size of the sintered strips may also be a factor that contributed to the low strip elongation. The conventional understanding in metallurgy is that an increase in grain size is accompanied by an increase in ductility [45]. However the elongation of the sintered strips may also be influenced by the strip thickness $(t)$ to grain size $\left(D_{g}\right)$ ratio i.e., $\left(t / D_{g}\right)$, as shown in a study by Takebe et al. [46]. The study by Takebe et al. investigated the effect of grain size and sheet thickness on the tensile properties of ASTM grade 1 titanium sheet, and found that there is an optimum $\left(t / D_{g}\right)$ ratio for a particular sheet thickness which produces the best elongation. It was found that within certain grain size ranges, an increase in grain size reduces the sheet elongation. Although the study by Takebe et al. researched the effect of the $\left(t / D_{g}\right)$ ratio on the tensile properties of wrought titanium sheets, this relation may also be applicable to DPR sintered strips.

The study by Takebe et al. investigated sheet sizes of $0.5 \mathrm{~mm}$ and lower, and found that a $0.3 \mathrm{~mm}$ sheet attained its greatest elongation at a $t / \mathrm{D}_{\mathrm{g}}$ ratio of 5 . In the present study, the highest elongation was produced by sintering at $1200{ }^{\circ} \mathrm{C}$ for $60 \mathrm{~min}$, and the corresponding $\mathrm{t} / \mathrm{D}_{\mathrm{g}}$ ratio of the strips was 6.8. Although the titanium strips used in this study were produced via a powder metallurgy process, and the sheet that was analyzed in the study by Takebe et al. was produced by the wrought-ingot process, the optimum $t / D_{g}$ ratios in both studies are very comparable. Thus, the effect of sheet thickness on grain size ratio may well have been a factor that significantly influenced tensile elongation in this study.

It was found that the tensile elongation of the strips increased when the sintering temperature was increased from $1100{ }^{\circ} \mathrm{C}$ to $1200^{\circ} \mathrm{C}$. Strips that were sintered at $1100{ }^{\circ} \mathrm{C}$ for $60 \mathrm{~min}$ and $90 \mathrm{~min}$ and at $1200^{\circ} \mathrm{C}$ for $30 \mathrm{~min}$ and $60 \mathrm{~min}$, were found to have the greatest elongation in this study. However, the strips that were sintered at $1300{ }^{\circ} \mathrm{C}$ displayed the lowest tensile elongation in this study. The increase in the tensile elongation as the sintering temperature increased from $1100{ }^{\circ} \mathrm{C}$ to $1200{ }^{\circ} \mathrm{C}$ is due to an increase in strip density, although contamination also did increase in the strips. It is likely that grain growth also contributed to the increase in strip ductility. The strips that were sintered at $1300{ }^{\circ} \mathrm{C}$ had the lowest elongation in this study, as the strips were the most contaminated. The relatively large grains present in the strips that were sintered at $1300{ }^{\circ} \mathrm{C}$ may have also reduced the strips elongation via the aforementioned phenomena. 


\subsubsection{Ultimate Tensile Strength}

The ultimate tensile strength (UTS) of the sintered titanium strips is represented as mean results with standard deviation in Figure 12. It was found that an increase in sintering temperature and time increased the UTS of the sintered titanium strips. Generally, the significant factors which affect the tensile properties of a PM product are porosity, microstructure and contamination [47]. The tensile strength of titanium increases with an increase in interstitial contamination, through solid solution strengthening [40]. The hardness testing results confirm that interstitial contamination of the strips did increase with sintering temperature and time, and thus contamination is a factor which raised the UTS of the strips.

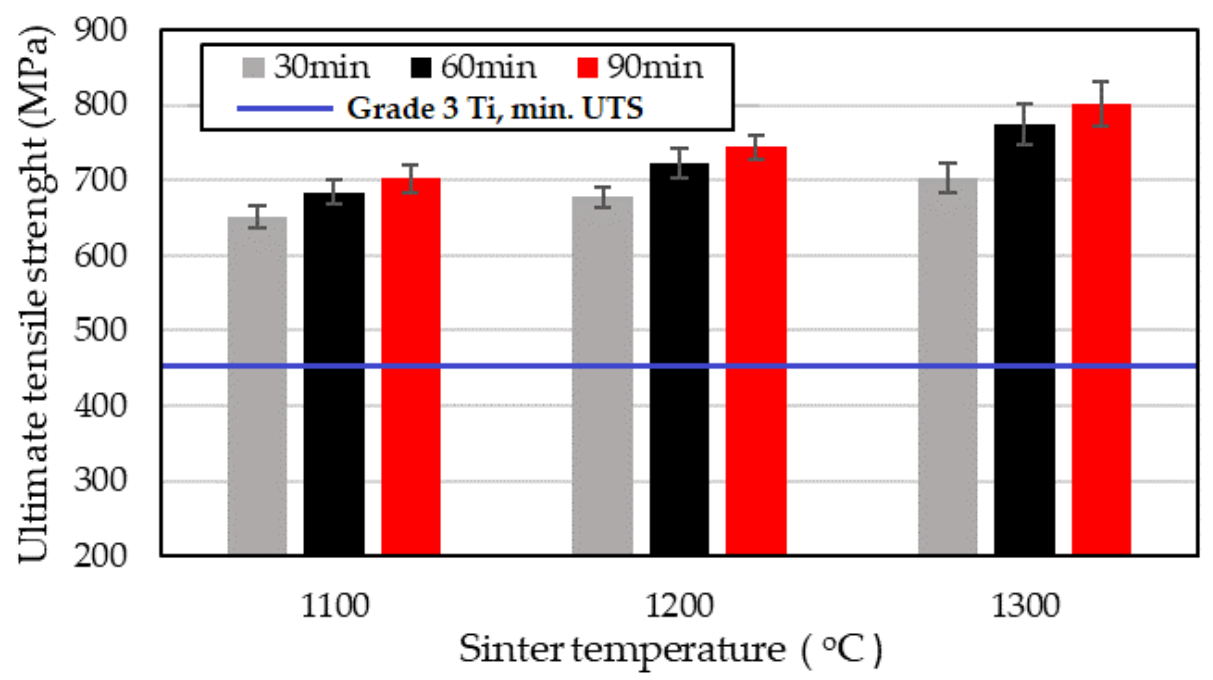

Figure 12. Ultimate tensile strength of the sintered titanium strips.

An increase in density (a reduction in porosity) of a PM material increases the tensile strength of the PM material. For example, it was indicated in a review study that an increase in density raises the tensile strength of Ti-6AL-4V compacts [47]. Thus, the increase in density of the strips is a factor which raises the UTS of the sintered strips. According to the Hall-Petch equation [45], an increase in grain size is expected to lower the tensile strength of the material. As shown in Section 3.4.2, the grain size of the strips increased with an increase in sinter temperature and time, and thus grain growth contributed to lowering the UTS of the strips. The net effect of the increase in strip contamination, density and grain size is noted as an increase in the UTS of the strips.

\subsubsection{Elastic Modulus}

The elastic moduli of the sintered strips are tabulated in Table 5, represented as mean values with the standard deviation of the results. The elastic moduli values of the sintered strips compare well with the elastic modulus of pure titanium, which ranges between 103 and $105 \mathrm{GPa}$ [48]. The variation in the results is believed to be due to changes in porosity, contamination and grain size.

Table 5. Elastic moduli of the sintered titanium strips.

\begin{tabular}{cccc}
\hline Sinter Temperature $\left({ }^{\circ} \mathbf{C}\right)$ & $\mathbf{3 0} \mathbf{~}$ in $\mathbf{( G P a )}$ & $\mathbf{6 0} \mathbf{~}$ in $\mathbf{( G P a )}$ & $\mathbf{9 0} \mathbf{~ m i n}(\mathbf{G P a})$ \\
\hline 1100 & $97.1 \pm 5.2$ & $98.3 \pm 3.6$ & $99.2 \pm 4.4$ \\
1200 & $98.9 \pm 6.1$ & $101.0 \pm 3.3$ & $103.9 \pm 3.1$ \\
1300 & $102.5 \pm 2.7$ & $105.1 \pm 2.8$ & $108.2 \pm 3.8$ \\
\hline
\end{tabular}




\subsection{Microstructural and Grain Size Analysis}

\subsubsection{Sintered Strip Microstructure}

The microstructural images of the width cross section of the sintered titanium strips are shown in Figure 13. It is observed from Figure 13 that there is an increase in the grain size as the sintering temperature increased, and as the sinter hold time increased. The number of grains is also reduced as sinter temperature and time increase. It is also observed that the number and size of pores is reduced as sinter temperature and time increase, and the pores changed from an irregular to a rounded shape as sintering progressed. The equiaxed grain shape which is noted is a typical characteristic of recrystallization [49].

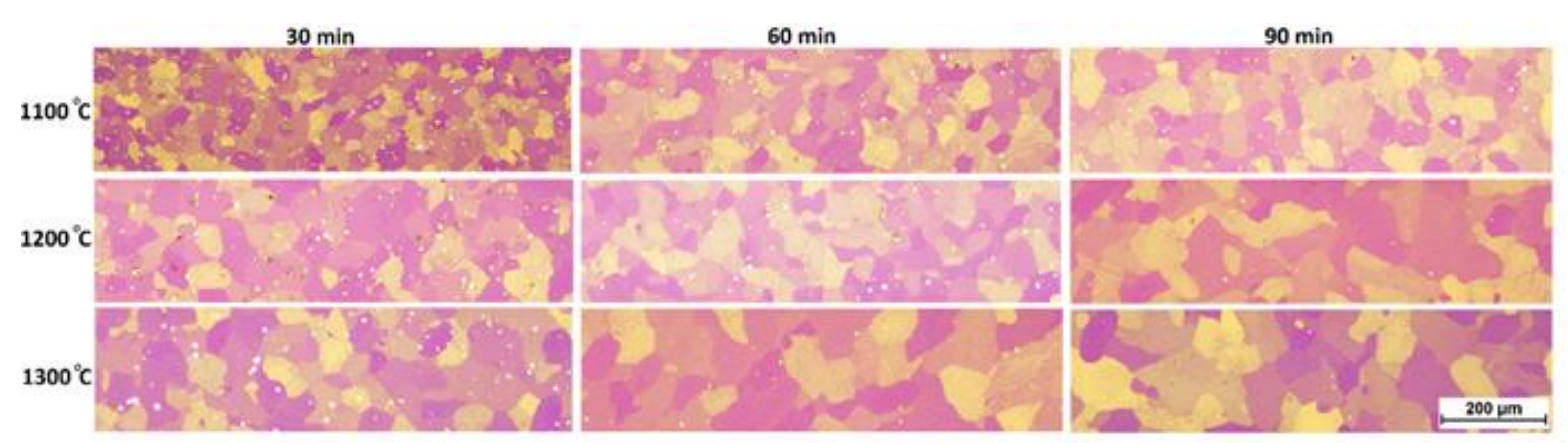

Figure 13. Nine microstructural images of the width cross section of the sintered titanium strips.

The increase in grain size and reduction in pore size with increasing sinter temperature, is due to mass transport within the strip. Surface and bulk diffusion are mass transport mechanisms that occur during sintering, however bulk diffusion is responsible for material densification [50]. Bulk mass transport refers to grain boundary diffusion and volume diffusion, and becomes more active at higher temperatures [50], which drove grain growth and pore reduction.

From observation of the size and quantity of pores in the microstructures presented in Figure 13, it is clear that during $90 \mathrm{~min}$ of sintering, most densification occurred during the first $30 \mathrm{~min}$ to $60 \mathrm{~min}$ of sintering. This effect became greater as the sintering temperature increased, due to the higher driving force for densification that is created by higher temperatures [51]. This observation is in agreement with the density results in Section 3.1, which also revealed that the greatest densification gains in this study occurred during $30 \mathrm{~min}$ to $60 \mathrm{~min}$ of sintering. Sintering for $60 \mathrm{~min}$ or more drove most pores away from the grain boundaries, and the pores became spherical in appearance, which is a typical characteristic of the final stages of sintering [50]. The aforementioned observations are also congruent with solid-state sintering theory.

As mentioned in Section 3.1, fine powders create higher sintering rates than coarse powders, which is beneficial to reducing sinter durations. In addition, a high green density also reduces sintering time by reducing the time duration for each stage of sintering. Sintering theory states that when loosely compacted powder particles are sintered, the particles will naturally go through all stages of sintering, such as necking, the intermediate stage and the final stage. However, if the powder particles are compacted to a high density, the coordination number of the powder particles increases, and consequently, some early stages of sintering will not occur [50]. The coordination number is the number of particle contacts on each particle [52]. The elimination of the early sintering stages reduces sintering time, which is a benefit of sintering with a high green density. This phenomenon has been observed in this study, as the microstructural images of the grains in Figure 13 show little evidence of necking being present as early as after $30 \mathrm{~min}$ of sintering. Thus, the conventional neck formation and neck growth stages during sintering in this study proceeded very rapidly or did not occur as an isolated stage due to the initial high green density $(\sim 90 \%)$ of the titanium strips. 


\subsubsection{Grain Size Analysis}

The grain size of the sintered strips represented as mean values with standard deviation and the typical grain size of wrought-ingot titanium sheet are tabulated in Table 6. It was found that the grain size of the sintered strips increased with an increase in sinter temperature and sinter time. The strips that were sintered at $1300^{\circ} \mathrm{C}$ for $90 \mathrm{~min}$ contained the largest grains, with a grain size of approximately $66 \mu \mathrm{m}$, and the strips that were sintered at $1100{ }^{\circ} \mathrm{C}$ for $30 \mathrm{~min}$ contained the smallest grains with a grain size of approximately $33 \mu \mathrm{m}$. Although the titanium powder used in this study has a particle size of $-45 \mu \mathrm{m}$, due to some sintering conditions, the grain size was lower than $45 \mu \mathrm{m}$. This is caused by new grains forming within the original cold-worked powder particles, through recrystallization. It is also noted that the grain size of the sintered strips in this study is significantly larger than the grain size of titanium sheet produced by the wrought-ingot process.

Table 6. The grain size of the sintered titanium strips.

\begin{tabular}{ccccc}
\hline $\begin{array}{c}\text { Sinter Temperature } \\
\left({ }^{\circ} \mathbf{C}\right)\end{array}$ & $\mathbf{3 0} \mathbf{m i n}(\boldsymbol{\mu m})$ & $\mathbf{6 0} \mathbf{m i n}(\boldsymbol{\mu m})$ & $\mathbf{9 0} \mathbf{m i n}(\boldsymbol{\mu m})$ & $\begin{array}{c}\text { Wrought-Ingot } \\
\text { Ti Sheet }(\boldsymbol{\mu m})\end{array}$ \\
\hline 1300 & $55.68 \pm 6.27$ & $59.77 \pm 7.26$ & $66.39 \pm 8.16$ & \\
1200 & $41.18 \pm 5.45$ & $46.69 \pm 6.12$ & $59.91 \pm 7.74$ & 12.9 to 20 \\
1100 & $33.20 \pm 4.74$ & $36.45 \pm 5.58$ & $43.11 \pm 6.73$ & {$[46,53-55]$} \\
\hline
\end{tabular}

\section{Discussion}

\subsection{Density}

It is significant that most of the strip densification occurs during the first $30 \mathrm{~min}$ to 60 min of sintering, because if green densities $>95 \%$ are utilized, near-full density can be expected within this short sintering time range, making the continuous sintering process more favorable. This is a useful result, as many steel components are sintered continuously at a commercial level for $30 \mathrm{~min}$ to $60 \mathrm{~min}$ at temperatures in the range of $1000{ }^{\circ} \mathrm{C}$ to $1250{ }^{\circ} \mathrm{C}$ [5]. Thus, if higher green density strips can be sintered within $30 \mathrm{~min}$ to $60 \mathrm{~min}$, and if the sintered properties of the strips meet ASTM B265 standards, this roll-and-sinter process could match the production levels of processes that sinter steel components.

The sintering temperatures of $1100{ }^{\circ} \mathrm{C}$ to $1300{ }^{\circ} \mathrm{C}$, which were investigated in this study, are also the typical temperatures that can be achieved by continuous furnaces in industry $[56,57]$. The temperatures investigated were also found to be effective for sintering titanium compacts in other studies [58].

As mentioned in Section 3.1, fine powders were selected for this study, however, fine Ti-HDH powder particles have the general tendency to have a higher oxygen content than coarse Ti-HDH powder particles [25]. Increasing oxygen content adversely affects the ductility of titanium and increases the strength of titanium via solid solution strengthening [59]. The problem of high oxygen content in fine titanium powders can be overcome by using deoxygenation techniques to produce powders with low oxygen as summarized in [3]. However, deoxygenated powders are more expensive than the conventional Ti-HDH powders, due to the additional processing steps.

Diffusion bonding, which is usually performed under high-vacuum or inert atmospheres, is the application of high pressure and temperature to two contacting surfaces, with the aim of driving diffusion between the two surfaces to create a bond. However, long durations are generally needed to create a sufficient bond. To reduce processing times, techniques such as the use of interlayers and impulse pressure-assisted diffusion bonding (IPADB), etc., have been investigated, as described in a review paper on IPADB [60]. The results of this study may also be beneficial to reducing the time duration for diffusion bonding of certain metals, as it has been shown that fine compacted titanium powder can be heated within short durations to bond together to achieve near-full density. 


\subsection{Tensile Properties}

\subsubsection{Tensile Elongation}

In Section 3.3.1, it was mentioned that oxygen, nitrogen and carbon atoms from the argon atmosphere occupy the octahedral interstitial sites in the HCP titanium lattice. The presence of these atoms distorts the HCP lattice and causes lattice expansion. This was demonstrated in a study by R. Montanari et al. [61], which found that the crystal lattice of Ti$6 \mathrm{Al}-4 \mathrm{~V}$ expands when heated up to $600{ }^{\circ} \mathrm{C}$, due to absorption of gases such as oxygen and nitrogen that are present in the argon atmosphere, as well as due to thermal expansion. In the study by R. Montanari et al., high-temperature X-ray diffraction (XRD) measurements were conducted on Ti-6Al-4V powder samples that were heated up to $600{ }^{\circ} \mathrm{C}$, under an atmosphere of a commercially pure grade of argon. It was also demonstrated in the study by R. Montanari et al. that gases become entrapped in the lattice once the samples have cooled to room temperature, as it was found that the lattice parameters increased from the original values. The $\mathrm{c} / \mathrm{a}$ ratio of the HCP lattice was found to increase from 1.5954 to 1.5989. Although no XRD measurements were taken in the present study, it is expected that the HCP lattice of the titanium strips also expanded due to the absorption of oxygen and nitrogen.

To improve the ductility of the titanium strips, it is recommended that the argon gas be further purified to remove all impurities present in the gas before it is used in the sintering process. It is also recommended that in future work strips be rolled to green densities of $95 \%$ or greater, and be sintered under similar experimental procedures, as discussed in this study. A DPR strip with a green density $>95 \%$, may reduce the required sinter time and temperature, to achieve full or near-full density, as found in this study. High green density strips can be produced by repeated cold rolling operations, hot rolling, as well as through optimization of the PSD of the titanium powder $[62,63]$. The use of thicker green strips can also improve ductility, as a greater percentage of the strip cross section would be protected from atmospheric contamination, in comparison to sintering thin green strips. Thereafter, to achieve the desired strip thickness, the thick strips can be cold rolled and annealed.

\subsubsection{Ultimate Tensile Strength}

The UTS of the sintered strips in this study exceeds the minimum tensile strength requirement for $\mathrm{CP}$ grade 3 titanium, as stipulated in ASTM B265, which is $450 \mathrm{MPa}$. The measured UTS range of the strips in this study are also comparable, with the UTS of CP-Ti sheet that was produced by the CSIRO DPR and hot-rolling densification process, reporting a titanium sheet with a UTS range of 793 to $806 \mathrm{MPa}$ [62].

\subsection{Grain Size Analysis}

For comparative purposes, the grain size of the strips in Table 6 is compared to the grain size of conventional titanium sheet. The grain size of titanium sheet that is produced by the wrought-ingot process is dependent on the degree of cold work induced in the sheet and the recrystallization temperature of the production process [64]. In addition, each titanium sheet manufacturer has a unique sheet manufacturing process in some respects [10]. It is thus expected that the grain size of conventional titanium sheet will vary between manufacturers, within a certain limit. From a survey of studies [46,53-55], it was found that the grain size of conventional $\mathrm{CP}$ titanium sheet, in the thicknesses range of $0.3 \mathrm{~mm}$ to $1.6 \mathrm{~mm}$, varies between 12.9 and $20 \mu \mathrm{m}$. Thus, the sintered strips that were produced in this study have relatively larger grains than the grains present in conventional titanium sheet. The grain size of the sintered strips could be further refined by cold rolling and annealing [64].

\subsection{Continuous Sintering Furnaces}

This study has shown that titanium DPR strips can be sintered to achieve high density and acceptable properties in short durations, such as 30-60 min. If higher green densities are used, shorter sinter durations and improved properties are anticipated. Thus, it is 
beneficial to describe a potential continuous sintering process that could be used to sinter titanium sheet continuously.

There are several types of continuous furnaces that are used commercially for heat treatment, such as the pusher furnace, the roller hearth furnace, the mesh belt furnace, etc. However, based on the low mass per unit area of the titanium sheet, approximately $1.2 \mathrm{~kg} \mathrm{~m}^{-2}$, the mesh belt furnace would be the most suitable furnace for sintering titanium sheet continuously. The load value of $1.2 \mathrm{~kg} \mathrm{~m}^{-2}$ was determined for a green DPR titanium sheet of $90 \%$ green density and $0.3 \mathrm{~mm}$ thickness. Mesh belt furnaces are commonly used in industry for heat treatment of metals, sintering of metals, etc., and an example of a typical mesh belt furnace is illustrated in Figure 14. A major concern with sintering titanium continuously is the contamination of the argon furnace atmosphere with air, which leaks into the furnace. The atmosphere in the furnace can be controlled with atmosphere control features such as fiber curtains and nitrogen gas curtains which are illustrated in Figure 14 [65].

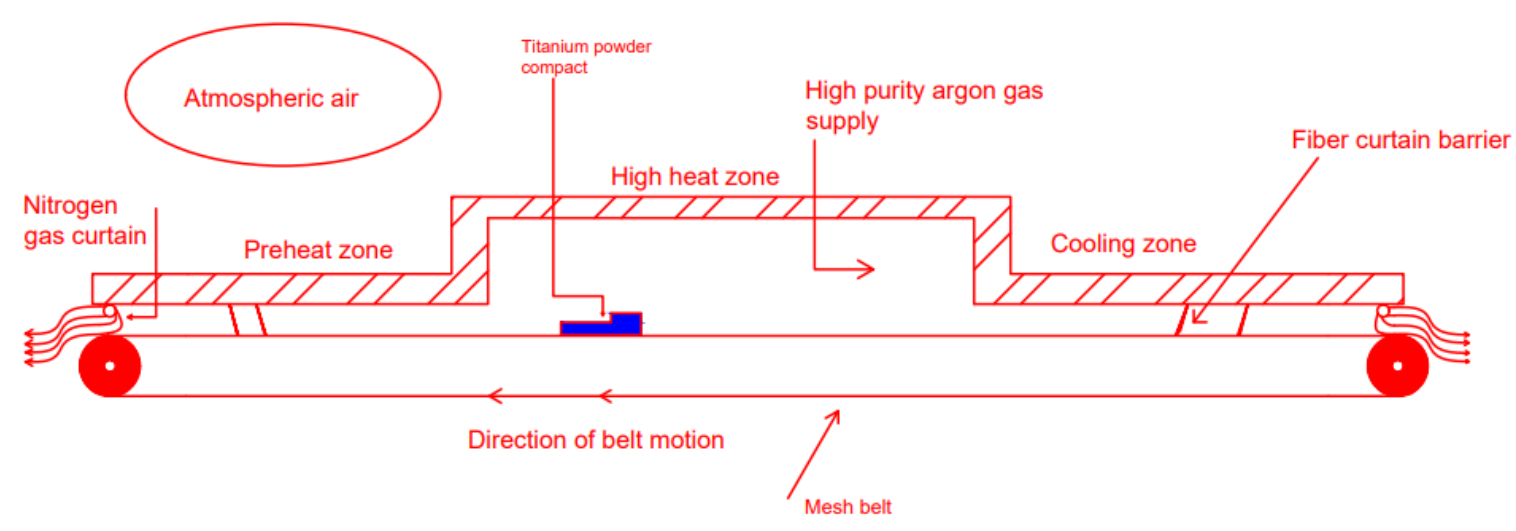

Figure 14. A continuous mesh belt furnace (adapted from [12]).

The nitrogen gas curtain reduces ingress of air into the furnace by creating a laminar flow of nitrogen gas across the entrance and the exit of the furnace. The fiber curtains are layers of fibers that together form an adaptive wall, which surrounds the part as it enters and exits the furnace, thus reducing air ingress into the furnace. The fiber curtain also reduces the loss of inert atmosphere and heat from the furnace, which are two production cost drivers which influence the unit cost of titanium sheet produced [65].

As the furnace gas exits the furnace inlet and exit, it also serves to hinder air ingress. A common misunderstanding is that as the velocity of gas exiting the furnace increases, it is more effective at reducing air ingress. However, this is not always true as it has been shown that a high exit atmosphere velocity could increase air ingress into the furnace through the production of vortices. This is an additional consideration that must be accounted for to operate a continuous furnace that sinters titanium, and will require determination of an optimum exit gas velocity. [65]

As mentioned in Section 2.2, there was no further flow of argon gas into the furnace tube during sintering in this study, however, in a continuous industrial furnace, an argon gas flow rate is required due to atmosphere loss from the entrance and exit of the furnace. The continuous flow of argon gas over the titanium sheet being sintered may introduce more impurities to the sheet, and thus the gas flow rate and time at maximum temperature should be minimized. Thus, the results of this study represent the 'best-case' properties of sintering titanium sheet continuously. In a real context, if the titanium strips in this study were sintered under a continuous flow of argon, reduced properties, in comparison to those achieved in this study, would be anticipated.

The hardware and technology currently used in mesh belt furnaces may also need to be adapted to sinter DPR titanium sheets, for example, the belt material and the heat source. Mesh belt furnaces transport the workload through the furnace on a mesh belt. Belts that 
are typically used in furnaces that operate at temperatures of $1100{ }^{\circ} \mathrm{C}$ to $1200{ }^{\circ} \mathrm{C}$ are made of materials such as 314 stainless steel, Inconel 601, $\mathrm{NiCr} 70 / 30$, etc. [66]. However, these aforementioned belt materials will contaminate the CP titanium sheet at high temperatures, and thus belts made from alternate materials should be used to transport titanium sheet in a continuous furnace. Materials such as molybdenum and zirconia are used to support titanium compacts during sintering [67], and are therefore candidate materials for a belt that will transport titanium compacts in a furnace.

Electric heating and organic fuels are the two heat sources that are commonly used in furnaces [5]. Electric heating is recommended for continuous sintering of titanium, as it is a clean source of heat, unlike combustion of organic fuels which produces combustion by-products. However, if the use of organic fuels as a heat source is found to be more economical than electric heating, it can be used via indirect heating of the furnace chamber [5].

\section{Conclusions}

This study investigated the as-sintered properties of DPR titanium strips that were sintered under argon atmosphere. The green strips were of $89.8 \%$ density and were produced from $-45 \mu \mathrm{m}$ Ti-HDH powder. The strips were sintered at temperatures in the range of $1100{ }^{\circ} \mathrm{C}$ to $1300{ }^{\circ} \mathrm{C}$, and were held at maximum temperature for durations that ranged from $30 \mathrm{~min}$ to $90 \mathrm{~min}$.

It was found that sintered densities of $96-99 \%$ can be achieved in industrially acceptable sinter times. An increase in sintering temperature and time resulted in an increase in surface hardness of the titanium strips, due to an increase in contamination absorption from the argon atmosphere. Sintering strips at $1100{ }^{\circ} \mathrm{C}$ for $60 \mathrm{~min}$ and $90 \mathrm{~min}$ and at $1200{ }^{\circ} \mathrm{C}$ for $30 \mathrm{~min}$ and $60 \mathrm{~min}$ produced the highest tensile elongations in this study, which were in the range of $4-5.5 \%$. However, this elongation range does not meet the minimum elongation requirements of ASTM grade 3 titanium. Strips that were sintered at $1300{ }^{\circ} \mathrm{C}$ displayed low elongation in the range of $1-2 \%$. This is due to the high levels of contamination pick-up during sintering at $1300{ }^{\circ} \mathrm{C}$. The grain size of the strips may have also contributed to the low tensile elongation found in this study.

However, the UTS of all the sintered strips in this study did exceed $450 \mathrm{MPa}$, which is the minimum UTS requirement of ASTM grade 3 titanium. The results of this study indicate that titanium strips that are sintered continuously could meet ASTM B265 requirements (for grade 3 titanium) if strips with a green density in excess of $95 \%$ and a purified argon atmosphere are utilized.

Author Contributions: Conceptualization, A.G., C.B. and S.C.; methodology, A.G., C.B. and S.C.; software, C.B. and S.C.; validation, A.G., C.B. and S.C.; formal analysis, A.G., C.B. and S.C.; investigation, A.G., C.B. and S.C.; resources, C.B. and S.C.; data curation, A.G., C.B. and S.C.; writing-original draft preparation, A.G.; writing-review and editing, C.B. and S.C.; visualization, A.G., C.B. and S.C.; supervision, C.B. and S.C.; project administration, C.B. and S.C.; funding acquisition, C.B. All authors have read and agreed to the published version of the manuscript.

Funding: This research was funded by Department of Science and Innovation of South Africa through the Titanium Centre of Competence. The article processing charge (APC) was not funded.

Institutional Review Board Statement: Not applicable.

Informed Consent Statement: Not applicable.

Data Availability Statement: Not applicable.

Acknowledgments: The CSIR Manufacturing Cluster department is gratefully acknowledged for assisting with much of the analysis in this study, and for sponsoring the titanium powder used for this study. The authors also acknowledge Llanley Simpson, Director of Mining and Minerals Beneficiation at Department of Science and Innovation, and Robert Tshikhudo, Competence Area Manager at the CSIR Manufacturing Cluster, for providing funding and resources to conduct this study.

Conflicts of Interest: The authors declare no conflict of interest. 


\section{References}

1. Donachie, M.J. Introduction to selection of titanium alloys. In Titanium: A Technical Guide; ASM International: Materials Park, OH, USA, 2000; pp. 5-11.

2. Froes, F.H.; Gungor, M.N.; Imam, M.A. Cost-affordable titanium: The component fabrication perspective. J. Miner. Met. Mater. Soc. 2007, 59, 28-31. [CrossRef]

3. Fang, Z.Z.; Paramore, J.D.; Sun, P.; Chandran, K.S.R.; Zhang, Y.; Xia, Y.; Cao, F.; Koopman, M.; Free, M. Powder metallurgy of titanium: Past, present and future. Int. Mater. Rev. 2018, 63, 407-459. [CrossRef]

4. Nippon, S.C. Product Catalog. Available online: https://www.nipponsteel.com/product/catalog_download/pdf/T001en.pdf (accessed on 19 January 2020).

5. German, R.M. Sintering practice. In Sintering Theory and Practice, 1st ed.; Wiley-Interscience: New York, NY, USA, 1996; Volume 1, pp. 450-496.

6. Steytler, M.; Knutsen, R.D. Identifying challenges to the commercial viability of direct powder rolled titanium: A systematic review and market analysis. Materials 2020, 13, 1-24. [CrossRef]

7. Fray, D.J. Novel methods for the production of titanium. Int. Mater. Rev. 2008, 53, 317-325. [CrossRef]

8. TIMET. Products. Available online: https://www.timet.com/ (accessed on 20 December 2020).

9. Nippon, S. Manufacturing Process. Available online: https://www.nipponsteel.com/en/product/titan/process/ (accessed on 12 January 2020).

10. Donachie, M.J. Ingot metallurgy and mill products. In Titanium: A Technical Guide, 2nd ed.; ASM International: Materials Park, OH, USA, 2000; Volume 1, pp. 25-30.

11. Liu, Y.; Luo, X.; Li, Z. Microstructure evolution during semisolid powder rolling and post-treatment of 7050 aluminum alloy strips. J. Mater. Process. Technol. 2014, 214, 165-174. [CrossRef]

12. Smith, D. Sintering furnaces for the PM industry. Metal. Powder Rep. 1990, 45, 605-610. [CrossRef]

13. Park, N.K.; Lee, C.H.; Kim, J.H.; Hong, J.K. Characteristics of powder-rolled and sintered sheets made from HDH Ti-powders Key Eng. Mater. 2012, 520, 281-288. [CrossRef]

14. Cantin, G.M.D.; Gibson, M.A. Titanium sheet fabrication from powder. In Titanium Powder Metallurgy: Science, Technology and Applications, 1st ed.; Qian, M., Froes, F.H., Eds.; Butterworth-Heinemann: New York, NY, USA, 2015; pp. $383-403$.

15. Zhang, Y.; Knutsen, R.D. A Study of Direct Powder Rolling Route for CP-Titanium. Master's Thesis, University of Cape-Town, Cape Town, South Africa, 2015.

16. Duz, V.; Matviychuk, M.; Klevtsov, A.; Moxson, V. Industrial application of titanium hydride powder. Metal. Powder Rep. 2017, 72, 30-38. [CrossRef]

17. Muth, T.; Barnes, J.E.; Yamamoto, Y.; Paliwal, M.; Peter, W.H.; Chen, W.; Jolly, B.; Stone, N.A.; Cantin, G.M.D.; Smith, R.; et al. Titanium sheet fabricated from powder for industrial applications. J. Miner. Met. Mater. Soc. 2012, 64, 566-571. [CrossRef]

18. Moxson, V.S.; Duz, V.A. Process of Direct Powder Rolling of Blended Titanium Alloys, Titanium Matrix Composites and Titanium Aluminides. US Patent 2006/0147333 A1, 6 July 2006.

19. National Research Council. Titanium: Past, Present and Future; The National Academy Press: Washington, DC, USA, 1983. [CrossRef]

20. Yu, C. Ti Powder Sintering: Impurity, Sintering Atmosphere and Alloy Design. Ph.D. Thesis, University of Auckland, Auckland, New Zealand, 2014.

21. German, R.M. Thermodynamic and kinetic treatments. In Sintering: From Empirical Observations to Scientific Principles, 1st ed.; Butterworth-Heinemann: Waltham, MA, USA, 2014; pp. 183-223.

22. Muchavi, N.S. Effects of Thermal Processing of Blended and Roll Compacted Ti-6Al-4V Strips on Microstructure and Properties. Master's Thesis, University of Johannesburg, Johannesburg, South Africa, 2018.

23. Table of Chemical Composition. Certificate of Chemical Compositional Analysis; LH-20190709-03, Baoji Lihua Non-ferrous Metals Co.Ltd.: Baoji, China, 17 August 2019.

24. ASTM-B265-08b. Standard Specification for Titanium and Titanium Alloy Strip, Sheet and Plate; American Society for Testing and Materials International: West Conshohocken, PA, USA, 2008. [CrossRef]

25. Barbis, D.P.; Gasior, R.M.; Walker, G.P.; Capone, J.A.; Schaeffer, T.S. Titanium powders from the hydride-dehydride process. In Titanium Powder Metallurgy: Science, Technology and Applications, 1st ed.; Qian, M., Froes, F.H., Eds.; Butterworth-Heinemann: New York, NY, USA, 2015; pp. 101-116.

26. Afrox. Specification data sheet: Baseline 5.0; Afrox: Gauteng, South Africa, 2017.

27. ASTM-B962-08b. Standard Test Method for Density of Compacted or Sintered Powder Metallurgy (PM) Products using Archimede's Principle; American Society for Testing and Materials International: West Conshohocken, PA, USA, 2008.

28. ASTM-B933-16. Standard Test Method for Micro Indentation Hardness of Powder Metallurgy (PM) Materials; American Society for Testing and Materials International: West Conshohocken, PA, USA, 2016. [CrossRef]

29. ASTM-E8/E8M-08. Standard Test Methods for Tension Testing of Metallic Materials; American Society for Testing and Materials: West Conshohocken, PA, USA, 2008. [CrossRef]

30. ASTM-E83-16. Standard Practice for Verification and Classification of Extensometer Systems; American Society for Testing and Materials International: West Conshohocken, PA, USA, 2016. [CrossRef] 
31. ASTM-E111-04. Standard Test Method for Young's Modulus, Tangent Modulus, and Chord Modulus; American Society for Testing and Materials International: West Conshohocken, PA, USA, 2004. [CrossRef]

32. ASTM-E3-11. Standard Guide for Preparation of Metallographic Specimens; American Society for Testing and Materials International: West Conshohocken, PA, USA, 2011. [CrossRef]

33. Geels, K.; Ruckert, M. Chapter 13: Specimen preparation. In Metallographic and Materialographic: Specimen Preparation, Light Microscopy, Image Analysis and Hardness Testing, 1st ed.; ASTM International: West Conshohocken, PA, USA, 2007 ; pp. 416-420.

34. Taylor, B.; Weidmann, E. Metallographic Preparation of Titanium: Struers Application Notes; Struers: Ballerup, Denmark, 2016.

35. ASTM-E112-13. Standard Test Methods for Determining Average Grain Size; American Society for Testing and Materials: West Conshohocken, PA, USA, 2013. [CrossRef]

36. German, R.M. Microstructure and processing relations in solid state sintering. In Sintering Theory and Practice, 1st ed.; WileyInterscience: New York, NY, USA, 1996; p. 143.

37. Robertson, I.M.; Schaffer, G.B. Review of densification of titanium based powder systems in press and sinter processing. Powder Metall. 2010, 53, 146-162. [CrossRef]

38. Robertson, I.M.; Schaffer, G.B. Some effects of particle size on the sintering of titanium and a master sintering curve model. Metall. Mater. Trans. A 2009, 40A, 1968-1979. [CrossRef]

39. Donachie, M.J. Machining. In Titanium: A Technical Guide, 2nd ed.; ASM International: Materials Park, OH, USA, 2000; pp. 313-326.

40. Donachie, M.J. Understanding the metallurgy of titanium. In Titanium: A Technical Guide, 2nd ed.; ASM International: Materials Park, OH, USA, 2000; pp. 13-21.

41. Kofstad, P. High-temperature oxidation of titanium. J. Less Common Met. 1967, 12, 449-464. [CrossRef]

42. Nakajima, H.; Koiwa, M. Review: Diffusion in titanium. ISIJ Int. 1991, 31, 757-766. [CrossRef]

43. Arensburger, D.S.; Pugin, V.S.; Fedorchenko, I.M. Properties of electrolytic and reduced titanium powders and sinterability of porous compacts from such powders. Sov. Powder Metall. Metal. Ceram. 1968, 7, 362-367. [CrossRef]

44. Conrad, H. Effect of interstitial solutes on the strength and ductility of titanium. Prog. Mater. Sci. 1981, 26, 123-403. [CrossRef]

45. Askeland, D.R.; Phule, P.P. Imperfections in the atomic and ionic arrangements. In The Science and Engineering of Materials, 4th ed.; Brooks/Cole-Thomson Learning: Boston, MA, USA, 2003; Volume 1, p. 154.

46. Takebe, H.; Mori, K.; Takahashi, K.; Fujii, H. Effects of Thickness and Grain Size on Tensile Properties of Pure Titanium Thin Gauge Sheets. In Proceedings of the 13th World Conference on Titanium, San Diego, CA, USA, 16-20 August 2016; pp. 491-494.

47. Wang, H.; Sun, P.; Fang, Z.Z. A critical review of mechanical properties of powder metallurgy titanium. Int. J. Powder Metall. 2010, $46,45-57$.

48. RMI. Titanium Alloy Guide; RMI Titanium Company: Pittsburgh, PA, USA, 2000.

49. Huda, Z. Chapter 14: Recrystallization and grain growth. In Metallurgy for Physicists and Engineers: Fundamentals, Applications and Calculations, 1st ed.; Taylor and Francis Group: Boca Raton, FL, USA, 2020; pp. 311-319.

50. German, R.M. Solid state sintering fundamentals. In Sintering Theory and Practice, 1st ed.; John Wiley and Sons: New York, NY, USA, 1996; Volume 1, pp. 69-111.

51. German, R.M. Introduction to sintering. In Sintering Theory and Practice, 1st ed.; John Wiley and Sons: New York, NY, USA, 1996; Volume 1, p. 8.

52. German, R.M. Sintering measurement techniques. In Sintering Theory and Practice, 1st ed.; Wiley-Interscience: New York, NY, USA, 1996; Volume 1, pp. 23-66.

53. Smith, K.K.; Kassner, M.E. Through-thickness compression testing of commercially pure (grade 2) titanium thin sheet to large strains. J. Metall. 2016, 2016, 1-11. [CrossRef]

54. Tan, M.J.; Zhu, X.J. Dynamic recrystallization in commercially pure titanium. J. Achiev. Mater. Manuf. Eng. 2006, 18, $183-186$.

55. Zhang, X.H.; Tang, B.; Zhang, X.L.; Kou, H.C.; Li, J.S.; Zhou, L. Microstructure and texture of commercially pure titanium in cold deep drawing. Trans. Nonferrous Met. Soc. China 2011, 22, 496-502. [CrossRef]

56. Nabertherm. Thermal Process Technology; Nabertherm: Lilienthal, Germany, 2019.

57. CM Furnaces. Continous Wire, Strip and Tube Annealing Furnaces; CM Furnaces: Bloomfield, NJ, USA, 2015.

58. Qian, M. Cold compaction and sintering of titanium and its alloys for near-net-shape or preform fabrication. Int. J. Powder Metall. 2010, 46, 29-44. [CrossRef]

59. Wasz, M.L.; Brotzen, F.R.; Mclellan, R.B.; Griffin, A.J. Effect of oxygen and hydrogen on mechanical properties of commercial purity titanium. Int. Mater. Rev. 1996, 41, 1-12. [CrossRef]

60. Alhazaa, A.; Haneklaus, N.; Almutairi, Z. Impulse pressure assisted-assisted diffusion bonding (IPADB): Review and outlook. Metals 2021, 11, 1-12. [CrossRef]

61. Montanari, R.; Costanza, G.; Tata, M.E.; Testani, C. Lattice expansion of Ti-6AL-4V by nitrogen and oxygen absorption. Mater. Charact. 2006, 59, 334-337. [CrossRef]

62. Stone, N.; Cantin, D.; Gibson, M.; Kearney, T.; Lathabai, S.; Ritchie, D.; Wilson, R.; Yousuff, M.; Rajakumar, R.; Rogers, K. Implementing the Direct Powder Route for Titanium Mill Product: Continuous Production of CP Sheet. Mater. Sci. Forum 2009, 618-619, 139-142. [CrossRef]

63. German, R.M. Sintering densification for powder mixtures of varying distribution width. Acta Metall. Mater. 1992, 40, $2085-2089$. [CrossRef] 
64. Lutjering, G.; Williams, J.C. Commercially pure (CP) titanium and alpha alloys. In Titanium, 2nd ed.; Springer: Berlin, Germany, 2007; Volume 1, pp. 175-201.

65. Silva, G.R.C.; Philips, T.; Dwyer, J.J.; Zurecki, Z. Techniques and tips to optimize, control and stabilize the atmosphere inside a continous sintering furnace. Mater. Sci. Forum. 2012, 728, 404-411. [CrossRef]

66. The Furnace Belt Company Limited. Product Catalog; The Furnace Belt Company Limited: Mississauga, ON, Canada, $2002 ;$ p. 22.

67. German, R.M. Sintering practice. In Sintering: From Empirical Observations to Scientific Principles; Elsevier: Oxford, UK, 2014; pp. 471-509. 